\title{
Mythical Thinking, Scientific Discourses and Research Dissemination
}

\author{
Sven Hroar Klempe
}

Published online: 2 April 2011

(C) The Author(s) 2011. This article is published with open access at Springerlink.com

\begin{abstract}
This article focuses on some principles for understanding. By taking Anna Mikulak's article 'Mismatches between 'scientific' and 'non-scientific' ways of knowing and their contributions to public understanding of science" (IPBS 2011) as a point of departure, the idea of demarcation criteria for scientific and non-scientific discourses is addressed. Yet this is juxtaposed with mythical thinking, which is supposed to be the most salient trait of non-scientific discourses. The author demonstrates how the most widespread demarcation criterion, the criterion of verification, is self-contradictory, not only when it comes to logic, but also in the achievement of isolating natural sciences from other forms of knowledge. According to Aristotle induction is a rhetorical device and as far as scientific statements are based on inductive inferences, they are relying on humanities, which rhetoric is a part of. Yet induction also has an empirical component by being based on senseimpressions, which is not a part of the rhetoric, but the psychology. Also the myths are understood in a rhetorical (Lévi-Strauss) and a psychological (Cassirer) perspective. Thus it is argued that both scientific and non-scientific discourses can be mythical.
\end{abstract}

Keywords Science communication - Demarcation · Myths · Theory of science

\section{Introduction}

To talk about understanding should be an easy task. However it is rather the opposite. As belonging to the same species understanding is apparently something the human beings have in common. Yet lack of understanding is probably one of the most widespread demarcation criteria for discerning groups. Women do not understand men, adults do not understand adolescents, citizens do not understand

S. Hroar Klempe $(\bowtie)$

Department of Psychology, NTNU, Trondheim, Norway

e-mail: hroar.klempe@svt.ntnu.no 
politicians and laymen do not understand scientists. This lack of understanding among the groups is mostly reciprocal. In this respect it is important to investigate what this lack of understanding between the groups might happen to be about.

This is exactly what Anna Mikulak is attempting at in her article "Mismatches between 'scientific' and 'non-scientific' ways of knowing and their contributions to public understanding of science" (IPBS 2011). One of the most interesting aspects of this article is the author's perspective on narratives and their structure as having a role in creating conflicts between these groups. "One dramatic framing device that easily fits within a typical narrative structure is that of conflict or controversy between two well-defined groups" (Mikulak 2011 p. 16). This is of course a fundamental aspect of narratives in general, and it is adopted in media discourses in several ways. We find it in fiction series, in commercials, in feature articles and even in the news. There is however one additional aspect that also characterizes these communicational appearances. That is the aspect of reconciliation that ends the conflict. This is exactly what appears in Mikulak's example from Lancet too. Wakefield et al., (1998) "noted that for eight of the twelve children studied, parents reported that behavioral symptoms of developmental disorder emerged shortly after MMR vaccination" (Mikulak 2011 p. 5). Since media also reported this article a deep conflict was established between the authorities who had made this vaccination obligatory and the population. This conflicted lasted for a while, but in "February, 2010, The Lancet officially retracted the 1998 Wakefield study" (Mikulak 2011 p. 8). Then the conflict had got its reconciliation. Yet the conflict was not between Wakefield et al. and the population, but all the other researchers and the authority on the one hand and Wakefield et al. and the population on the other.

\section{The mythical}

The narrative structure that is stated in this example therefore is the conflictresolution structure. Yet there is an additional factor that also seems to count. The retraction of the article came 12 years after it had been published. The conflict in other words lasted for a long time, and it was kept alive by bringing in new perspectives that either supported the one or the other side of the conflict. This is touching another requirement of contriving a balanced presentation. A feature in a newspaper is not properly balanced unless it manages to follow up with presenting several arguments from both sides. This brings in an element of repetition. However the different arguments do not represent repetition in a strict sense. It is not the same group that prevails with their arguments all the time, it is rather new groups of researchers or offended that are introduced to support the one or the other perspective, and often with new arguments for the same. The narrative structure therefore is also characterized by an element of variation. By the terms, conflict, repetition, variation and reconciliation, the structure of the mediated narrative in this case seems to be captured. These terms however are exactly what the anthropologist Claude Lévi-Strauss characterized as mythical (Lévi-Strauss, 1963, 1979, 1981). And of course there are studies that conclude that the mythical structure is a fundamental and uniting characteristic of different mediated communicational forms (Klempe 1993). 
However the mythical is not quite easy to grasp in its whole extent. It is not just Lévi-Strauss that has elaborated this term. His theories are depending very much on Ernst Cassirer, who introduced the myth in his studies on symbolic forms. Cassirer's neo-Kantian perspective is very much dealing with epistemological issues, which include understanding. On the other hand there is traditionally a sharp distinction between myths and science, despite the fact that Popper admitted that many remarkable scientific discoveries have had their origin in mythical thinking (Popper 1961). In Mikulak 2011 the narrative structure that characterizes the mediated presentation is supposed to stand in opposition to scientific discourses. This is an assumption of high general acceptance. This implies that the mythical can be understood as a negative demarcation criterion for scientific discourse. This is exactly what will be focused on in my paper, namely to examine to what extent mythical thinking can be regarded as a negative demarcation criterion for science.

\section{Demarcation}

The assumption of a certain criterion that can discern scientific from non-scientific statements is highly associated with logical positivism. Rudolph Carnap was one of the main figures in that philosophical movement, and he presented the so-called criterion of verification as the criterion for scientific knowledge (Carnap 1968). However Carnap was not the first scholar to make a clear and explicit distinction between scientific and non-scientific knowledge. This has been a part of the whole history of the theory of science, and can be traced back to Aristotle. His understanding of the demarcation criterion was very different from how Carnap defined it, and one may even say that their definitions contradicted each other. According to Aristotle the general and universal was a necessary requirement for talking about scientific knowledge. This may probably sound as coinciding with Carnap, but it does not. Despite the fact that both advocated general knowledge as a characteristic of scientific knowledge, they had very different opinions about how this was achieved. Carnap argued for an empirical approach, which implied that general knowledge was based on observations of the particular. Aristotle on the other hand stated that the particulars "cannot be objects of scientific knowledge" (Aristotle Posterior Analytics, Book I, Part 18). Thus the difference between Carnap and Aristotle is both crucial and critical when it comes to the question of demarcation. The fundamental question is to what extent science can be defined in terms of the particular or the universal, i.e. which of them that may count as a point of departure.

The two perspectives represent two different forms of logic. The Aristotelian logic is always derived from the general to the particular. This implies that the particular is included, but never as a point of departure. This Aristotelian logic therefore is characterized by deduction, which is to start with the general and universal and deduce to the singular and particular, and never the opposite way round. The latter contradicts deduction, and is called induction, which is to infer from the singular and particular to the general. Aristotle also often discusses induction, but in the Analytics, induction has a quite peripheral role. The reason is quite simple, namely that it is only valid as an inference in two different contexts, one is in practical learning and the other is in mathematics. In both cases one infer 
from the particular to the general. That is easy to do in mathematics because universals are already embedded in the particular. If a certain number is mentioned, the whole mathematical system, in which it is a part of, is presupposed at the same time. When it comes to practical knowledge, we just learn from trial and error; from our experiences through sensation, and the more we know from sensational experiences, the better we are in practical skills. Induction, therefore can give us knowledge, but according to Aristotle, this knowledge is not scientific, but practical and strongly connected to sensation.

In the Carnapian logic, observations form the point of departure. An observation is always given through the senses, which implies that an observation is defined in terms of the particular. Thus induction is with necessity a part of this logic, and this is the core aspect of the Carnapian demarcation criterion, namely that verification is depending on observations that can proof that something is true or not. By this Carnap has changed the logical premises for science. The universals do not form the point of departure, but it is regarded as an outcome. There are however two important elements Carnap introduces and includes in science that contrast Aristotle, and those are the role of sensations and the particular. Also Aristotle mentions these aspects, but not as a point of departure for logical and scientific inferences.

The places where Aristotle is investigating and elaborating sensation and induction as a basis for gaining knowledge is in On the Soul and in his Rhetorics, respectively. Those two theses of Aristotle form the basis for what we today would call "psychology" and "humanities" respectively. Thus the logic Carnap presented was not a result of isolating natural sciences from other dubious sciences. This was probably his aim, but his scientific approach was first of all based on observations, which is historically based on classical psychology and induction, of which the latter according to Aristotle primarily belonged to rhetoric; the art of persuasion. Logical positivism, in other words, represented an approach that was far away from the traditions of natural sciences, and some of this network's members took the consequences. The Norwegian philosopher Arne Naess, who was close to this circle when he wrote his doctoral thesis in the $1920 \mathrm{~s}$, developed the unending regress of observations in his contribution to the philosophy of science. The point was that research could not be objective unless there is an observer of the scientist's behaviour and an observer of the observer etc. (Slagstad 1980). In other words, he brought the whole problem back to psychology again, and Carnap gave at least up defending verification as a criterion for demarcation (Carnap 1966). Thus the belief in induction as a basis for scientific knowledge is from a logical point of view rather to be regarded as a qualitative than a quantitative approach. This demolishes at least one important aspect of the notion of demarcation, namely that modern natural sciences can be regarded as a model for social sciences and humanities.

\section{The myth as a negative demarcation criterion}

The one that really introduced myths and mythical thinking as a part of a general epistemological discussion was Ernst Cassirer (1874-1945). Out of his three volumes which present "The Philosophy of Symbolic Forms", the second from 1925 is dedicated to "Mythical Thought" (Cassirer 1955). Cassirer is often presented 
as a neo-Kantian, and this is true in the sense that he refers very much to Kant, but it is not true if one think that these references are limited just to Critique of pure Reason. It is rather the opposite. All the other theses of Kant are much more referred to, especially Critique of Judgment and not at least his writings in metaphysics. Hence Critique of Pure Reason is regarded in a broader context, which implies that the categorical understanding of what is and what is not science is omitted. What is prevailed however is the fundamental change in thinking that Kant represented; the Copernican revolution, which implied that acquired knowledge is not regarded as depending on external, but rather on internal constraints.

With these volumes on Symbolic Forms Cassirer aims at following up Kant's Copernican revolution, but he also "strives to broaden it" (Cassirer 1955 p. 29). This implies first of all that he wants to highlight the internal and subjective constraints that form our knowledge, but in addition he thinks that mythical thinking is the best pathway in an investigation of this. What characterizes mythical thinking, however, is the intuitive understanding of wholeness. "For mythical thinking all contents crowd together into a single plane of reality; everything perceived possesses as such a character of reality; the image like the word is endowed with real forces." (Cassirer 1955 p. 42.) Thus there are no clear distinctions between 'mere 'representation' and 'real' perception, between wish and fulfilment, between image and thing" (Cassirer 1955 p. 36). The mythical perspective therefore eliminates any clear distinctions between what is true and what is not true knowledge or what is science and what is not science. Thus when mythical thinking is introduced as a part of epistemology, the demarcation criterion in theory of science seems to having been eliminated completely.

This however represents a dangerous position. If all distinctions are eliminated and we stand left with a pure united wholeness, then all the elements will necessarily refer to everything and everything will be the same. This implies a sort of meaningless situation, because meaning in words are depending on distinctions and oppositions between them. Kant aimed at starting with exactly this united wholeness in his investigation of the pure reason, but he had no intention of ending up there. That is also true for Cassirer. He operates with distinctions, but these distinctions are not given as universals, but are given in their particularities. This is exactly the same as Peirce ends up with too. When he talks about "fixations of beliefs", and when he according to Mikulak describes four different, but lateral approaches to "fix" "our beliefs: tenacity, authority, a prioi [sic.], and science" Mikulak 2011 p. 4), there are different forms of knowledge that are situated differently, but without different values. This is strongly connected to his understanding of semiosis as an endless process.

Carnap too made a close relationship between making meaning and demarcation criteria; not verifiable statements were regarded as meaningless (Carnap 1968). One criterion was supposed to be sufficient for drawing a conclusion, and this criterion was regarded as having universal significance. In semiotics however-whether this is Peircian or Saussurian based - universality is lifted up to a superior level. Thus to make meaning out of language is a result of how language is used in terms of its perceived consequences or oppositions. Meaning therefore is a subjective and conventionally given entity. This implies that meaning is not a consequence of a universal criterion, but rather of its actual use. Thus from a semiotic, but also from a mythical perspective, a dichotomization of understandings, which a demarcation 
criterion is supposed to create, will occur as absurd by necessity. This is also true for a negative demarcation criterion, which the mythical very often is regarded to be.

\section{Research dissemination}

In this sense the case mentioned by Mukilak is of certain interest. It shows very clearly that the fundamental conflict is not primarily between scientists and nonscientists, but rather among scientists. This coincides not only with a semiotic perspective on meaning, but also with the Kuhnian understanding of how scientific knowledge is progressing. The basic suggestion in the logic of scientific revolutions is that also scientists prefer stability. However both the pragmatic thesis of Peirce and the Saussurian thesis of the arbitrary sign imply that stability is only achievable within a limited group for a limited span of time. Our conceptions of terms are changing, but the closer a group is, the slower will changes occur. No one can escape from changes, but well-defined groups can prevent themselves for a while, and through this apparently obtain stability. If scientific groups manage to do this, they will easily appear as trustworthy and reliable and by this be well accepted by governmental institutions. This will of course give them a kind hegemony and they will easily dominate the picture of research disseminations.

In this perspective it is difficult to talk about "the two cultures". There are many of them, but some few seem to dominate, because experts are apparently representing one group, laypeople will consequently form another. In this respect the "deficit model" for research dissemination is also problematic. According to Mikulak it says that "the reason people do not understand a particular scientific concept, or science more generally, is because they do not have sufficient information to do so" (Mikulak 2011 p. 7). This perspective presupposes a linear and mono causal relationship between addresser and addressee. This understanding of media is what scholars have regarded as historically limited to the first half of the twentieth century; the phase of all-powerful media (McQuail 1994). However also the audience are acting, and therefore "understanding arises from a two-way negotiation of meaning between expert approaches to knowledge and lay approaches to knowledge" (Mikulak 2011 p.10). This is an important correction of the "deficit model", and it underlines what is the semiotic and mythical understanding of the relationship between researchers and non-researchers, namely that there are no general principle that can tell the differences, but the differences in understandings appear between individuals. Thus an attempt at making a clear distinction between scientific discourse and research dissemination is embedded with the same problems as demarcation criteria.

\section{Conclusions}

On the one hand there is of course an immense difference between scientific and mythical discourses. Both Cassirer and Lévi-Strauss underline this fact. However what both of the two also underline is that mythical thinking is fundamental to all human being. The question therefore is rather how far a discourse can be distanced 
from mythical thinking, than getting completely rid of it. Thus we may easily find some reminiscences of mythical structures in scientific discourses too. On a more abstract level scientific discourses are characterized by two variants of rhetorical styles: conflict and confirmation. Because scientific discourse is characterized by preciseness each contribution does not reflect much more of mythical thinking than exactly these initial mythical aspects. In a bigger scale the elements of conflict, repetition, variation and resolution is present though, at least to a certain extent. This is probably most true when it comes to genres like articles and journals. This is not so much because of the genres themselves, but rather because a considerable growth in quantum may have influenced the form of these scientific genres. A vast amount of scientific articles will with necessity bring in an aspect of repetition, but also variation. A similar growth of journals presupposes and produces an aspect of conflict between different research groups. Resolutions may also occur, like the withdrawal of an article in Lancet Mikulak referred to. Thus one of the most fundamental problems with lack of understanding between scientists and nonscientists is probably more connected to a deficient in self-reflection in both groups. By not realizing all the irrational elements that unavoidably permeates discourses, either they are scientific or non-scientific, misunderstandings will by necessity occur as a salient trait of them.

Open Access This article is distributed under the terms of the Creative Commons Attribution Noncommercial License which permits any noncommercial use, distribution, and reproduction in any medium, provided the original author(s) and source are credited.

\section{References}

Aristotle. Posterior Analytics, http://classics.mit.edu//Aristotle/posterior.html

Carnap, R. (1966). Philosophical Foundations of Physics. New York: Basic Books, Inc., Publishers.

Carnap, R. (1968) Rudolf Carnap/utvalg og innledning ved Ingemund Gullvåg, Pax, Oslo

Cassirer, E. (1955). The philosophy of forms. Volume two: Mythical thought. New Haven: Yale University Press.

Klempe, H. (1993). Music, Text and image in Commercials for Coca-Cola. In J. Corner \& J. Hawthorn (Eds.), Communication studies. An introductory reader. London: Edward Arnold.

Lévi-Strauss, C. (1963). Structural anthropology (Vol. 1). Publishers, New York: Basic Books, Inc.

Lévi-Strauss, C. (1979). Myth and meaning. New York: Schocken Books.

Lévi-Strauss, C. (1981). The naked man. Introduction to a science of mythology:4. New York: Harper \& Row. McQuail, D. (1994). Mass communication theory (3rd ed.). London: Sage publication.

Mikulak, A. (2011). Mismatches between 'scientific' and 'non-scientific' ways of knowing and their contributions to public understanding of science. Integrative Psychological and Behavioral Science, 45, 2.

Popper, K. (1961). The logic of scientific discovery. New York: Basic Books, Inc.

Slagstad, R. (1980). Positivisme og vitenskapsteori: et essay om den norske positivismestriden. Oslo: Universitetsforlaget.

Wakefield, A.J. et al. (1998). Ileal-lymphoid-nodular hyperplasia, non-specific colitis, and pervasive developmental disorder in children. The Lancet, 351, 637-641.

Sven Hroar Klempe (born 1955) is associate professor in psychology at the Department of Psychology, NTNU, Trondheim. He graduated at the University of Oslo in 1983 and got his doctoral degree (Dr. art.) at the University of Trondheim in 1993. He is former a full professor in musicology, ass. prof. in media studies, a teacher and a journalist. His research is crossdisciplinary with an emphasis on theory of science, communication and the history of psychology. He has published some books in Norwegian in this areas and several articles in English and Norwegian. He was 2010/2011 on sabbatical at Clark University, Worcester, MA. 